\title{
Effects of Pioglitazone on Nonalcoholic Fatty Liver Disease in the Absence of Constitutive Androstane Receptor Expression
}

\author{
Hwa Young Ahn $\mathbb{D}^{1},{ }^{1}$ Hwan Hee Kim, ${ }^{2}$ Ji-Yeon Hwang, ${ }^{3}$ Changhun Park, ${ }^{4}$ \\ Bo Youn Cho, ${ }^{1}$ and Young Joo Park $\mathbb{B}^{2,5}$ \\ ${ }^{1}$ Department of Internal Medicine, Chung-Ang University College of Medicine, 102, Heukseok-ro, Dongjak-gu, \\ Seoul 06973, Republic of Korea \\ ${ }^{2}$ Seoul National University Hospital Biomedical Research Institute, 101, Daehak-ro, Jongno-gu, Seoul 03080, Republic of Korea \\ ${ }^{3}$ Preclinical Experimental Center, Seoul National University Bundang Hospital, 82, Gumi-ro 173 Beon-gil, Bundang-gu, \\ Seongnam-si, Gyeonggi-do 13620, Republic of Korea \\ ${ }^{4}$ Clinical Trials Center, Severance Hospital, Yonsei University Health System, 50-1, Yonsei-ro, Seodaemun-gu, \\ Seoul 03722, Republic of Korea \\ ${ }^{5}$ Department of Internal Medicine, Seoul National University College of Medicine, 101, Daehak-ro, Jongno-gu, \\ Seoul 03080, Republic of Korea \\ Correspondence should be addressed to Young Joo Park; yjparkmd@snu.ac.kr
}

Received 25 April 2018; Revised 23 August 2018; Accepted 17 September 2018; Published 27 September 2018

Academic Editor: Enrique Saez

Copyright (c) 2018 Hwa Young Ahn et al. This is an open access article distributed under the Creative Commons Attribution License, which permits unrestricted use, distribution, and reproduction in any medium, provided the original work is properly cited.

Nonalcoholic fatty liver disease or steatohepatitis (NAFLD/NASH) is a fatty liver disease that is closely related to obesity, diabetes, and dyslipidemia. Pioglitazone, which was developed as an antidiabetic drug, is known to improve NALFD. Pioglitazone is metabolized by multiple cytochrome P450 (CYP) enzymes, which are regulated by the xenobiotic receptor constitutive androstane receptor (CAR). In this study, we investigated the effects of pioglitazone on NAFLD by absence of CAR activity under high-fat (HF)-fed conditions. $\mathrm{CAR}^{-/-}$mice showed significant improvement in NALFD after 12 weeks of pioglitazone treatment compared to wild-type mice. This improvement in NAFLD persisted in $\mathrm{CAR}^{-/-}$mice regardless of blood pioglitazone concentration. The expression of lipogenesis genes in the liver, sterol-regulatory element binding protein-1c (SREBP-1c), and stearoyl-CoA desaturase (SCD)-1 was decreased after pioglitazone treatment in $\mathrm{HF}-\mathrm{fed} \mathrm{CAR}^{-/-}$mice. In addition, the expression of peroxisome proliferatoractivated receptor gamma 2 (PPAR $\gamma 2$ ) was decreased by pioglitazone in HF-fed CAR ${ }^{-1-}$ mice. Changes in SREBP-1c and PPAR $\gamma 2$ remained constant over short-term $(6 \mathrm{~h})$ pioglitazone and lipid injection. Our results showed that NAFLD was improved significantly by pioglitazone in a CAR deletion state. These results might be valuable because they suggest that interaction with CAR and pioglitazone/PPAR $\gamma 2$ may be important in regulating gene expression associated with NAFLD.

\section{Introduction}

Nonalcoholic fatty liver disease or steatohepatitis (NAFLD/ $\mathrm{NASH}$ ) is a fatty liver disease caused by diet-induced obesity. A recent epidemiologic study reported that the prevalence of NAFLD is $25.24 \%$ worldwide and $7.6 \%$ in children [1]. Obesity, type 2 diabetes mellitus, and dyslipidemia are closely related to NAFLD [2] and contribute to disease progression to liver fibrosis and cirrhosis [3]. Insulin resistance is a wellrecognized risk factor for NAFLD [4]. Hyperinsulinemia resulting from insulin resistance increases not only lipid synthesis, but also fatty acid uptake by hepatocytes because of increased lipolysis of adipocytes [2]. Lifestyle intervention (diet and exercise) and pharmacological treatments, such as vitamin E, pioglitazone, and pentoxifylline, are used to treat NAFLD [3].

Among these drugs, pioglitazone was shown to improve NAFLD in some human studies [5, 6]. Pioglitazone also decreases fasting and postprandial glucose levels by improving insulin sensitivity in type 2 diabetes mellitus [7] and is currently used as an antidiabetic medication. Pioglitazone acts by binding to the peroxisome proliferator-activated 
receptor gamma (PPAR $\gamma)$, a member of the nuclear receptor superfamily that plays a key role in glucose regulation and lipid metabolism [8]. Pioglitazone is extensively metabolized by hydroxylation and oxidation in the liver to form at least four primary metabolites (M-I, M-II, M-IV, and M-V) and two secondary metabolites (M-III and M-VI) [9]. Pharmacologically active M-IV and M-III are the main metabolites found in the human serum.

Pioglitazone is metabolized by multiple cytochrome $\mathrm{P} 450$ (CYP) enzymes, mainly CYP2C8, CYP3A4, and CYP2C9 [9, $10]$, which are regulated by the xenobiotic receptor constitutive androstane receptor (CAR) [11]. Previous studies showed that CAR can cause differences in drug efficacy by altering the degree of drug metabolism. For example, the acetaminophenmetabolizing enzyme CYP1A2, CYP3A11, and glutathione $S$-transferase are activated in a CAR-dependent manner after treatment with acetaminophen in wild-type mice and induced hepatotoxicity, but not in CAR null mice [12]. Therefore, CAR activity may affect the metabolism of pioglitazone and the effects of pioglitazone may vary according to the degree of metabolism.

In addition, the activity of CAR affects liver steatosis. The stimulation of CAR expression by a CAR agonist (TCPOBOP) reduced steatohepatitis in methionine cholinedeficient diet-fed mice [13]. CAR is a member of the NR1 subfamily; several other nuclear receptors such as pregnane $\mathrm{X}$ receptor; $\mathrm{PPAR} \alpha, \beta, \gamma$; liver X receptors $\alpha, \beta$; and farnesoid $\mathrm{X}$ receptor $\alpha$ are also members of the NR1 subfamily and are related to the pathogenesis of NAFLD [14]. Thus, interindividual differences in the effects of pioglitazone to NAFLD may be affected by CAR activity and interactions between several genes.

In this study, we hypothesized that the effect of pioglitazone on NAFLD is influenced by CAR activity. To confirm this hypothesis, we examined the effect of CAR deletion on changes in NAFLD and related gene expression induced by pioglitazone in the mouse liver.

\section{Material and Methods}

2.1. Animals and Study Drugs. $\mathrm{CAR}^{+/+}$(wild-type, C57BL/6J) mice were supplied by Orient Bio, Inc. (Seongnam, Korea). Wild-type mice were divided into two groups (control versus CAR activation). To induce CAR activation, once per week intraperitoneal injection of $3 \mathrm{mg} / \mathrm{kg}$ of TCPOBOP (SigmaAldrich, St. Louis, MO, USA) was administered. Homozygous CAR knockout $\left(\mathrm{CAR}^{-/-}\right)$mice were generated by gene targeting as previously described [15] and then backcrossed to $\mathrm{C} 57 \mathrm{BL} / 6 \mathrm{~J}$ mice to the tenth generation. They were backcrossed to $\mathrm{CAR}^{+/+} \mathrm{C} 57 \mathrm{BL} / 6 \mathrm{~J}$ mice (Orient Bio) and used as controls. Mice were housed at ambient temperature $(23 \pm$ $1^{\circ} \mathrm{C}$ ), with 12:12-h light-dark cycles and access to water ad libitum.

In the normal chow diet (Purina irradiated laboratory chow 38057, Purina Korea, Seoul, Korea) and high-fat diet (60 kcal \% fat diet, D12492, Research Diets, Inc., New Brunswick, NJ, USA) feeding condition, 8-10-week-old male $\mathrm{CAR}^{+/+}$(control and TCPOBOP-treated) and $\mathrm{CAR}^{-/-}$mice were assigned to vehicle or treatment groups according to the administration of pioglitazone hydrochloride (Takeda Chemical Industries, Osaka, Japan). Pioglitazone hydrochloride was administered at $10 \mathrm{mg} / \mathrm{kg} /$ day by the oral route by being mixed with the diet for 12 weeks. Each experimental group included at least 4 mice, and the experiment was repeated 3 times.

During administration of different concentrations of pioglitazone hydrochloride (Santa Cruz Biotechnology, Inc., Santa Cruz, CA, USA) to $\mathrm{CAR}^{+/+}$and $\mathrm{CAR}^{-/-}$mice $(1,3,10$, 20 , or $30 \mathrm{mg} / \mathrm{kg}$ ), pioglitazone was administered using sonde once daily for 14 days. Pioglitazone hydrochloride was dissolved in Solutol HS-15 (9\% in phosphate-buffered saline). Similar serum concentrations of pioglitazone were detected when we administered different concentration of pioglitazone to $\mathrm{CAR}^{+/+}$mice $\left(10\right.$ and $20 \mathrm{mg} / \mathrm{kg}$ ) and $\mathrm{CAR}^{-/-}$mice (1 and $3 \mathrm{mg} / \mathrm{kg}$ ).

To detect short-term changes of gene expression after pioglitazone treatment, we performed a short-term $(6 \mathrm{~h})$ experiment. Mice were divided into 4 groups of $\mathrm{CAR}^{+/+}$ and $\mathrm{CAR}^{-/-}$mice depending on whether pioglitazone and/or lipid was administered. Three mice were included in each group. Pioglitazone hydrochloride $(20 \mathrm{mg} / \mathrm{kg})$ and $3 \mathrm{~g} / \mathrm{kg}$ of $20 \%$ intralipid (LIPO MCT injection, Dongkook Pharmaceutical Co., Chungbuk, Korea) were administered via intraperitoneal injection.

All animals were sacrificed after fasting for $6 \mathrm{~h}$ starting from 06:00 a.m. Mice were anesthetized by intraperitoneal injection of Zoletil ${ }^{\circledR}$ (Virbac, Carros, France) and total body fat was measured by a small animal body composition analyzer, PIXImus (GE Healthcare, Little Chalfont, UK). The liver was quickly removed, weighed, and frozen in liquid nitrogen for RNA extraction. White and brown fat were also removed, weighed, and frozen in liquid nitrogen. The study protocol was approved by the Institutional Animal Care and Use Committee at the Seoul National University Bundang Hospital, Seongnam, Republic of Korea (BA1012-074/068-1).

\subsection{Measurement of Body Weight and Glucose Tolerance.} Body weight was monitored every week. Food intake was measured every 3 days. Blood glucose levels were checked with reagent strips read in a glucometer (ACCU-CHEK Active, Roche, Mannheim, Germany). An intraperitoneal glucose tolerance test was carried out after $12 \mathrm{~h}$ of fasting by intraperitoneal injection of $1 \mathrm{~g} / \mathrm{kg}$ glucose at 12 weeks after the experiments. Blood glucose levels from tail vein blood were determined using a glucometer before and 15, 30, 60, 90, and 120 min after glucose injection.

2.3. Measurement of Lipid Profile and Insulin. Serum total cholesterol, triglyceride, high-density lipoprotein cholesterol, and low-density lipoprotein cholesterol were determined with a Beckman Coulter AU480 automatic biochemistry analysis system (Brea, CA, USA) with reagent kits provided by the manufacturer. For lipid extraction, tissue were rinsed with ice cold PBS to remove excess blood thoroughly and small pieces and homogenized them in 100-200 $\mu \mathrm{L}$ PBS with a glass homogenizer on ice. The resulting suspension 
was stored overnight at $-20^{\circ} \mathrm{C}$. To further break to cell membranes, two freeze-thaw cycles were performed. After that, the homogenates were centrifuged for 5 minutes at 5000 $\mathrm{x} g$. The supernatant was used for assay. Triglyceride ELISA kit (Aviva Systems Biology, San Diego, CA, USA) and total cholesterol assay kit (BioVision Inc., Milpitas, CA) were used for assay. Insulin was measured using a mouse insulin ELISA kit (ALPCO Diagnostics, Windham, NH, USA) following the manufacturer's protocol.

2.4. Histological Analysis. The left lobes of the livers were removed, rinsed with PBS, fixed in $10 \%$ formaldehydePBS solution, and embedded in paraffin. Tissues were sectioned at $5 \mu \mathrm{m}$ thickness and stained with hematoxylin and eosin.

2.5. Measurement of Pioglitazone Concentration. The concentrations of pioglitazone were analyzed by high-performance liquid chromatography (Agilent 1200 series, Agilent Technologies, Santa Clara CA, USA). Pioglitazone hydrochloride was diluted in $50 \%$ acetonitrile to obtain a $100 \mu \mathrm{g} / \mathrm{mL}$ working solution. This working solution was diluted with blank plasma to prepare standard solutions of different concentrations $(5,10,50,100,500,1000$, and $2000 \mathrm{ng} / \mathrm{mL})$. This standard solution $(0.2 \mathrm{~mL})$ was mixed with $10 \mu \mathrm{L}$ of $1 \mu \mathrm{L} / \mathrm{mL}$ formoterol and $600 \mu \mathrm{L}$ of acetonitrile and then centrifuged for $5 \mathrm{~min}$ at $13,226 \times \mathrm{g}$. Next, $100 \mu \mathrm{g} / \mathrm{mL}$ of supernatant was mixed with $500 \mu \mathrm{L}$ of $5 \mathrm{mM}$ ammonium formate: acetonitrile (20:80, $0.1 \%$ trifluoroacetic acid). This mixture $(0.1 \mu \mathrm{L})$ was subjected to liquid chromatographymass spectrometry/mass spectrometry and the graphs were analyzed.

2.6. RNA Isolation and Quantitative Real-Time PCR. Total RNA was isolated from frozen liver and cells using TRIzol $^{\circledR}$ Reagent (Invitrogen, Carlsbad, CA, USA) according the manufacturer's instructions. First-strand cDNA was synthesized from $1 \mu \mathrm{g}$ of RNA using an Omniscript RT kit (Qiagen, Hilden, Germany). Quantitative RT-PCR was performed using SsoFast EvaGreen Supermix (BioRad Laboratories, Inc., Hercules, CA, USA) and CFX96 ${ }^{\mathrm{TM}}$ real-time PCR system (Bio-Rad Laboratories, Inc.). The sequences $\left(5^{\prime}\right.$ to $\left.3^{\prime}\right)$ for the primers were as follows: $\operatorname{PPAR} \alpha$, forward primer (AATCCTGTGCCAACCAGAAG), reverse primer (ATCGCCACTAAGGTGTCAGG); PPAR $\gamma 1$, forward primer (TGCAGCTCAAGCTGAATCAC), reverse primer (ACGTGCTCTGTGACGATCTG); PPAR $\gamma 2$, forward primer (TGCAGCTCAAGCTGAATCAC), reverse primer (CACGTGCTCTGTGACGATCT); peroxisome proliferator-activated receptor $\gamma$ coactivator 1 $\alpha$ (PGC- $1 \alpha)$, forward primer (AAGAGCGCCGTGTGATTTAC), reverse primer (TGCATTCCTCAATTTCACCA); fatty acid translocase, cluster of differentiation 36 (CD36), forward primer (AAACCAGTGCTCTCCCTTGA), reverse primer (CTGCACCAATAACAGCTCCA); sterolregulatory element binding protein-1c (SREBP-1c), forward primer (TGACCCGGCTATTCCGTGA), reverse primer (CTGGGCTGAGCAATACAGTTC); fatty acid synthase (FAS), forward primer (CCCTTGATGAAGAGGGATCA), reverse primer (CAAGGCGTTAGGGTTGACAT); stearoylCoA desaturase (SCD)-1, forward primer (AGGTGCCTCTTAGCCACTGA), reverse primer (CCAGGAGTTTCTTGGGTTGA); carnitine palmitoyltransferase 1 (CPT-1) $\alpha$, forward primer (ACAGTGGGACATTCCAGGAG), reverse primer (AAGGAATGCAGGTCCACATC); long-chain acylCoA dehydrogenase (LCAD), forward primer (TCACCACACAGAATGGGAGA), reverse primer (TTTCTCTGCGATGTTGATGC); microsomal triglyceride transfer protein (MTTP), forward primer (GTATTCCCACCTCAGCCAGA), reverse primer (GTCAGGCACGTCAAAGCATA); glyceralehyde-3-phosphate dehydrogenase (GAPDH), forward primer (TGTGTCCGTCGTGGATCT-GA), reverse primer (CCTGCTTCACCACCTTCTTGA).

2.7. Statistical Analysis. Statistical analysis was performed by nonparametric analysis by using the Mann-Whitney test. Statistical significance was assumed at $P<0.05$.

\section{Results}

3.1. Changes in Body, Liver, and Fat Weight and Glucose and Lipid Metabolism by Pioglitazone Treatment and Different CAR Activities in Diet-Induced Obesity Mice. The change in body weight in mice fed a high-fat (HF) diet for 12 weeks was not significant by pioglitazone treatment in $\mathrm{CAR}^{+/+}$and $\mathrm{CAR}^{-/-}$mice (Figure 1(a)). The percentage of total body fat was increased in pioglitazone-treated $\mathrm{CAR}^{+/+}$mice, but this effect was reversed by CAR deletion (Figure 1(b)). Amount of food intake was similar between groups (data shown). Liver weight did not differ between groups (Figure 1(c)). Although fasting insulin level showed no significant difference (Figure $1(\mathrm{~d})$ ), pioglitazone treatment significantly inhibited the increase in blood glucose level at all-time points in $\mathrm{CAR}^{-/-}$mice and significantly increased blood glucose in $\mathrm{CAR}^{+/+}$mice group except for at $120 \mathrm{~min}$ after glucose loading (Figure 1(e)). Serum total and high-density lipoprotein cholesterol levels were significantly higher in $\mathrm{CAR}^{-/-}$ mice than in $\mathrm{CAR}^{+/+}$mice. However, there was no significant change in lipid profiles after pioglitazone treatment (Figure 1(f)). Liver cholesterol and triglyceride were also not different after pioglitazone treatment (Figure $1(\mathrm{~g})$ ).

\subsection{Improvement of NAFLD in Pioglitazone-Treated $C A R^{-1-}$} Mice. In histologic examination, hepatic steatosis was slightly aggravated in $\mathrm{CAR}^{-/-}$mice (Figure 2(b)) compared with $\mathrm{CAR}^{+/+}$mice (Figure 2(a)), but was nearly completely abolished after TCPOBOP treatment, which is a strong activator of CAR (Figure 2(c)). After pioglitazone treatment, fat globules remained in the liver of $\mathrm{CAR}^{+/+}$mice (Figure $2(\mathrm{~d}))$. In contrast, liver steatosis was markedly improved by pioglitazone treatment in $\mathrm{CAR}^{-/-}$mice (Figure 2(e)). However, in TCPOBOP-treated mice, we observed no additional effect of pioglitazone on NAFLD (Figure 2(f)), possibly because the strong effects of TCPOBOP ameliorate fatty liver [16]. 


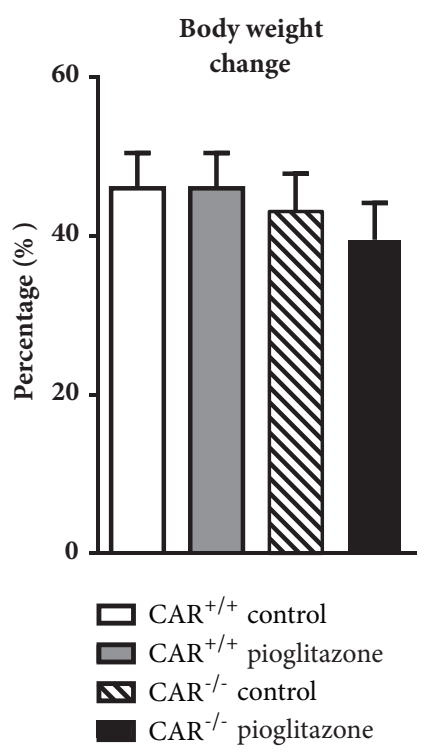

(a)

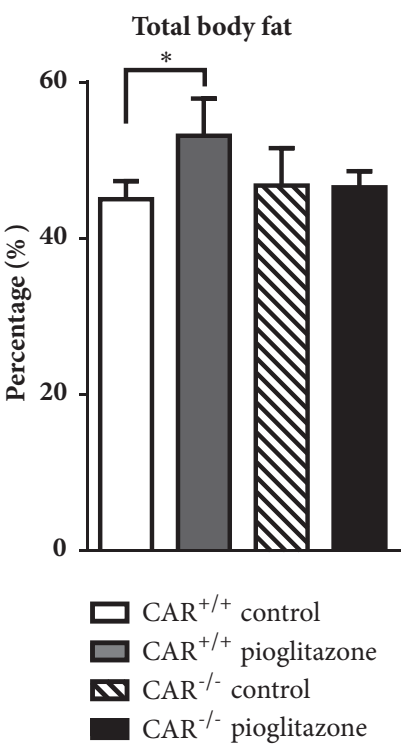

(b)
Liver weight

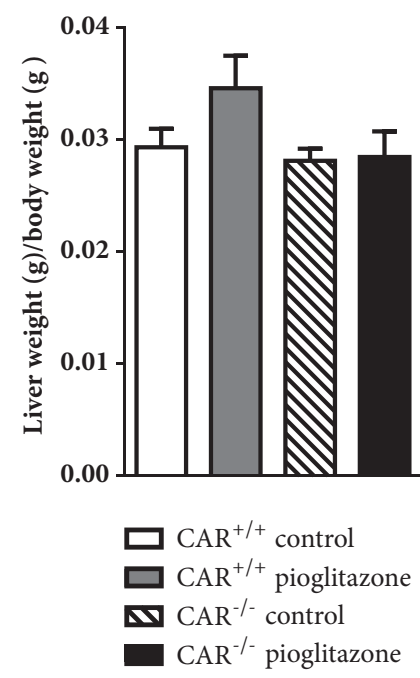

(c)
Fasting insulin

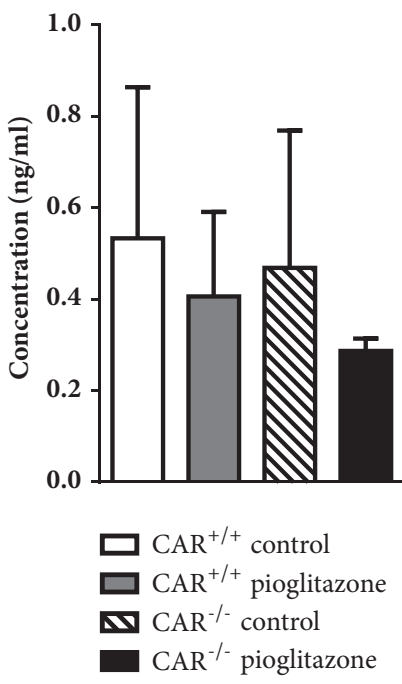

(d)
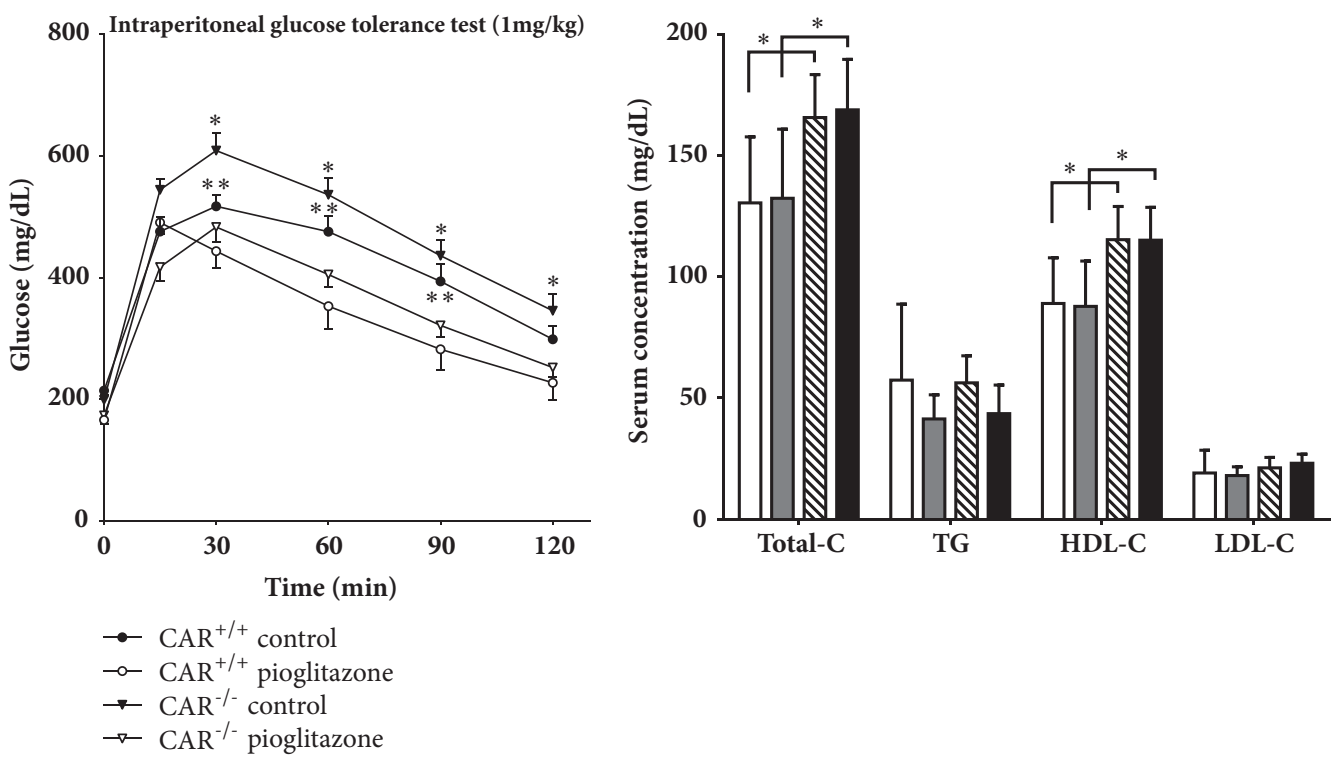

(e)

(f)

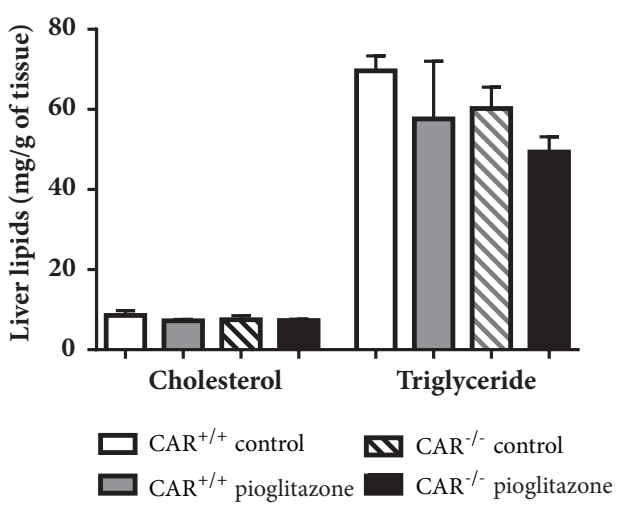

(g)

FIGURE 1: Metabolic changes according to CAR activity. (a) Rates of change in body weight by pioglitazone treatment after 12 weeks in $\mathrm{CAR}^{+/+}$and $\mathrm{CAR}^{-/-}$mice. (b) Total body fat changes after 12 weeks. (c) Liver weight after 12 weeks. (d) Fasting insulin level after 12 weeks. (e) Intraperitoneal glucose tolerance test after 12 weeks. $* \mathrm{p}<0.05, \mathrm{CAR}^{-/-}$control versus $\mathrm{CAR}^{-/-}$pioglitazone, $* * \mathrm{p}<0.05, \mathrm{CAR} \mathrm{R}^{+/+}$ control versus $\mathrm{CAR}^{+/+}$pioglitazone. (f) Lipid profile after 12 weeks. $* \mathrm{p}<0.05$. (G) Measurement of cholesterol and triglyceride in the liver. 


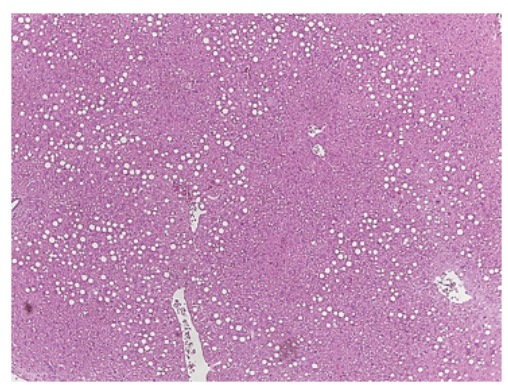

(a)

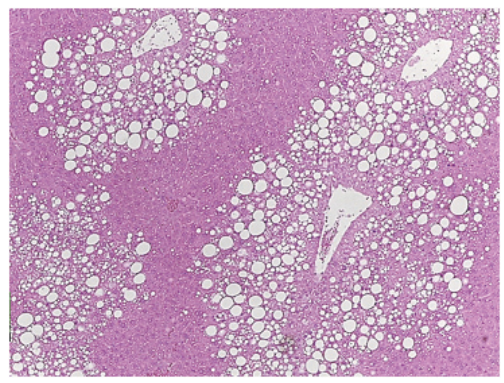

(d)

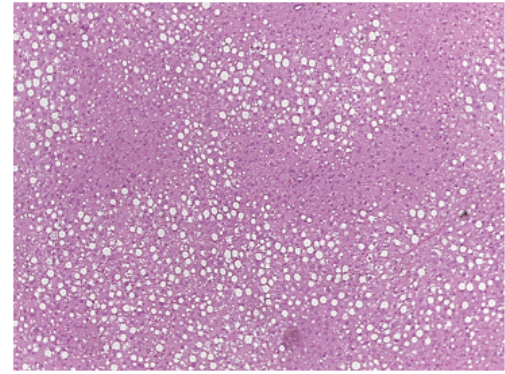

(b)

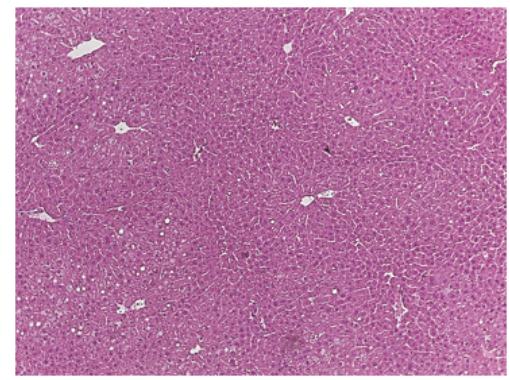

(e)

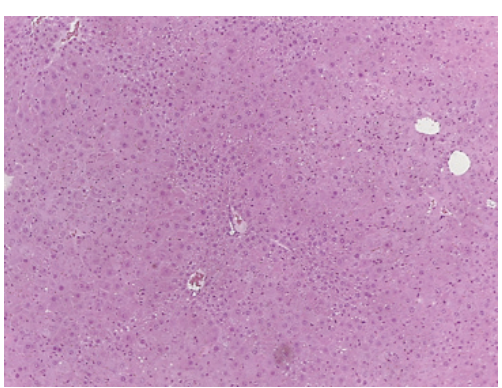

(c)

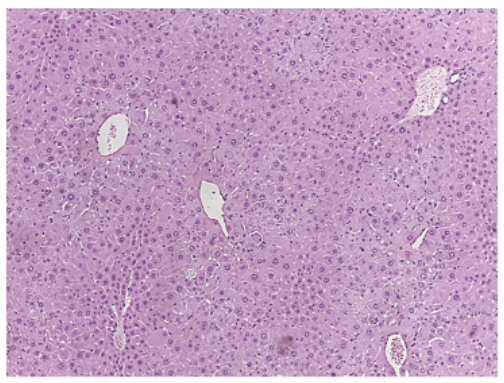

(f)

FIGURE 2: Hepatocyte fat accumulation after 12 weeks of pioglitazone treatment according to CAR activity. Representative hematoxylin

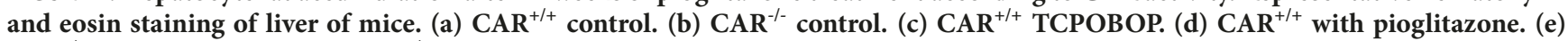
$\mathrm{CAR}^{-/-}$with pioglitazone. (f) $\mathrm{CAR}^{+/+}$TCPOBOP with pioglitazone.

3.3. Improvement of NAFLD in Pioglitazone-Treated CAR-/Mice Regardless of Blood Concentration of Pioglitazone. Because pioglitazone is mainly metabolized by CYP2C8 and CYP3A4 in vitro [17], serum concentrations of pioglitazone may be affected by CAR activity. Therefore, we measured the concentration of pioglitazone in three groups with different CAR activity. The mean concentrations of pioglitazone were $14.9 \pm 11.5,2054.0 \pm 1132.9$, and 4109.7 $\pm 606.2 \mathrm{ng} / \mathrm{mL}$ in $\mathrm{CAR}^{+/+}$with TCРОВOP, $\mathrm{CAR}^{+/+}$, and $\mathrm{CAR}^{-/-}$mice, respectively. Because TCPOBOP strongly stimulates CAR activity, we could not properly evaluate the effect of pioglitazone under ТСРОВOP treatment conditions. In addition, as pioglitazone induced expression of CAR target genes (CYP2B10 and CYP3A11, Supplementary Figure 1), we thought that the existence of CAR gene itself might interfere with the interpretation of the effect of pioglitazone on NAFLD. Thus, further analysis of the effects of pioglitazone on NAFLD by CAR activity was performed only in $\mathrm{CAR}^{+/+}$ and $\mathrm{CAR}^{-/-}$mice. To confirm whether the improvement of hepatic steatosis after pioglitazone in $\mathrm{CAR}^{-/-}$mice resulted from a higher concentration of pioglitazone or was related to the absence of CAR itself, we made similar serum pioglitazone concentrations for both $\mathrm{CAR}^{+/+}$and $\mathrm{CAR}^{-/-}$mice. We administered different concentrations of pioglitazone $(10,20$, and $30 \mathrm{mg} / \mathrm{kg}$ ) for 2 weeks with the HF diet to $\mathrm{CAR}^{+/+}$and $\mathrm{CAR}^{-/-}$mice and measured the pioglitazone concentration in the blood (Figure 3(a)). $\mathrm{CAR}^{-/-}$mice showed approximately 3-10-fold higher concentrations of pioglitazone compared to $\mathrm{CAR}^{+/+}$mice after receiving the same dose of pioglitazone. Based on these results, we administered 10 and $20 \mathrm{mg} / \mathrm{kg}$ of pioglitazone in $\mathrm{CAR}^{+/+}$mice and 1 and $3 \mathrm{mg} / \mathrm{kg}$ of pioglitazone to $\mathrm{CAR}^{-/-}$mice for 2 weeks in conjunction with a HF diet. We obtained similar serum concentrations of pioglitazone in $\mathrm{CAR}^{+/+}$and $\mathrm{CAR}^{-/-}$mice (Figure 3(b)). Next, we compared the hepatic steatosis of $\mathrm{CAR}^{-/-}$mice treated with 1 and $3 \mathrm{mg} / \mathrm{kg}$ of pioglitazone to that in $\mathrm{CAR}^{+/+}$ mice treated with 10 and $20 \mathrm{mg} / \mathrm{kg}$ of pioglitazone. Despite the similar serum concentrations of pioglitazone between $\mathrm{CAR}^{+/+}$and $\mathrm{CAR}^{-/-}$mice, a significant improvement in hepatic steatosis was persistently observed in $\mathrm{CAR}^{-/-}$mice (Figure 3(d) versus 3(g), 3(e) versus 3(h)). In $\mathrm{CAR}^{+/+}$mice, pioglitazone treatment showed no improvement in fatty liver compared with control mice (Figures 3(d), 3(e) versus Figure 3(c)). On the other hand, pioglitazone treatment was effective in the improvement of fatty liver in $\mathrm{CAR}^{-1-}$ mice compared to the control mice (Figures $3(\mathrm{~g})$, $3(\mathrm{~h}$ ) versus $3(\mathrm{f})$ ).

\subsection{Changes in Gene Expression Related to Hepatic Steatosis in} 12 Weeks of HF Diet Feeding to $\mathrm{CAR}^{-/-}$Mice after Pioglitazone Treatment. To investigate whether the mechanism among those related to the development of fatty liver was associated with the improvement in hepatic steatosis observed in HFfed $\mathrm{CAR}^{-/-}$mice with pioglitazone treatment, we analyzed changes in the mRNA expression of several well-known genes related to lipogenesis, hepatic lipid uptake, and fatty acid oxidation according to diet, pioglitazone, and CAR status (Figure 4). Expression of SREBP1c involved in lipogenesis was decreased after pioglitazone treatment in both chow 


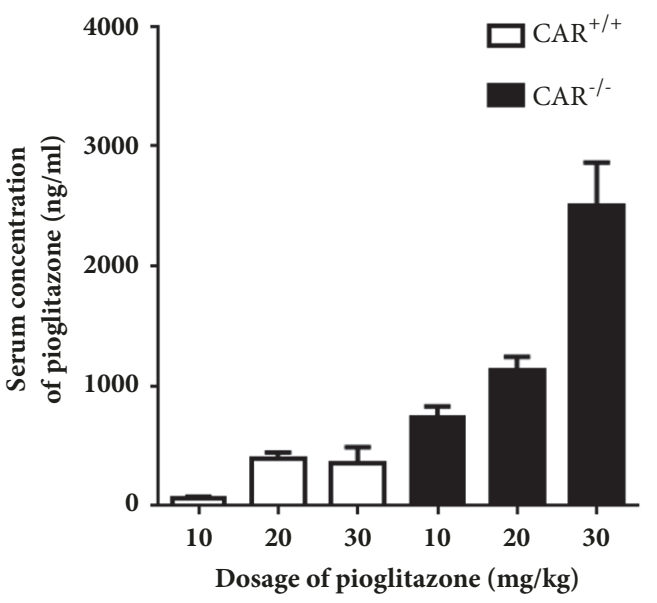

(a)

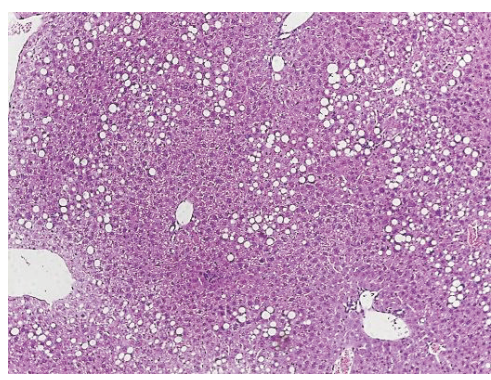

(c)

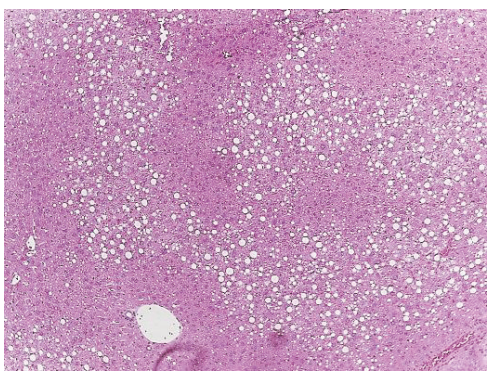

(f)

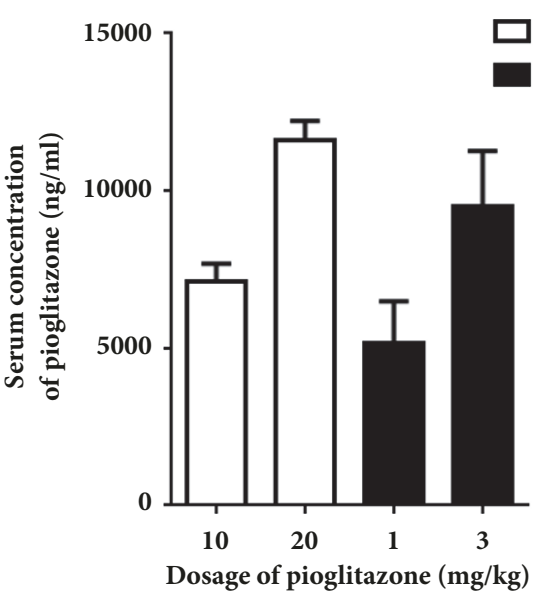

(b)

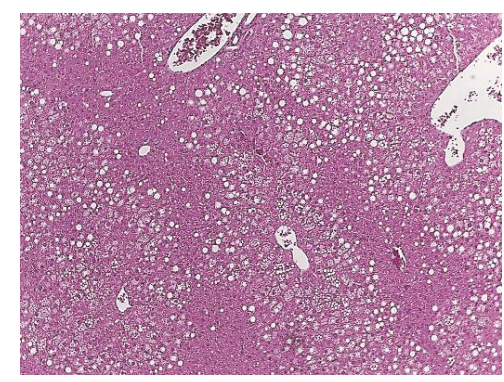

(d)

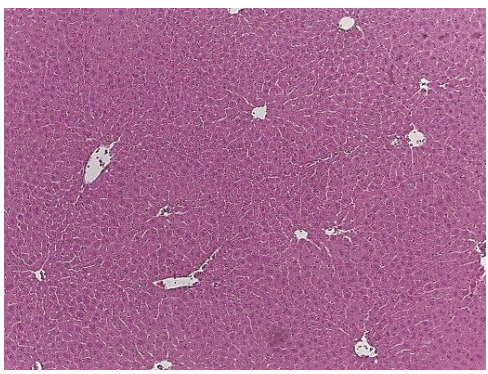

(g)

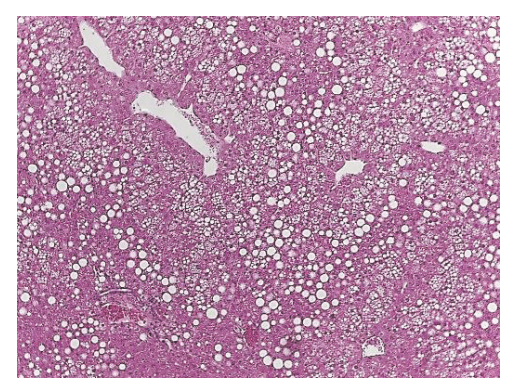

(e)

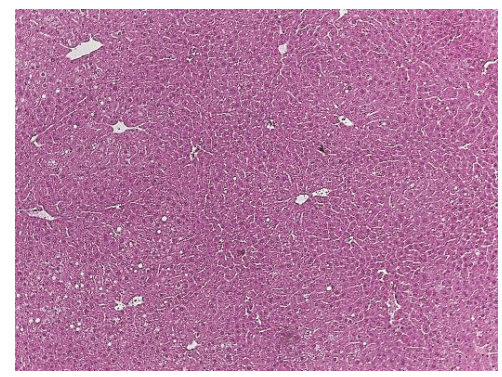

(h)

FIGURE 3: (a, b) Serum concentrations of pioglitazone in $\mathrm{CAR}^{+/+}$and $\mathrm{CAR}^{-/-}$mice after 2 weeks of pioglitazone treatment. (c-h) Liver histology when serum concentration of pioglitazone was similar between $C_{A A R^{+/}}$and $C_{A R}{ }^{-/}$mice. Serum concentration was similar between (d) and (g), and (e) and (h). (c) $\mathrm{CAR}^{+/+}$control (vehicle), (d) $\mathrm{CAR}^{+/+}$pioglitazone $10 \mathrm{mg} / \mathrm{kg}$, (e) CAR ${ }^{+/+}$pioglitazone $20 \mathrm{mg} / \mathrm{kg}$, (f) $\mathrm{CAR}^{-/-}$control (vehicle), (g) $\mathrm{CAR}^{-1-}$ pioglitazone $1 \mathrm{mg} / \mathrm{kg}$, (h) $\mathrm{CAR}^{-/-}$pioglitazone $3 \mathrm{mg} / \mathrm{kg}$.

and HF-fed CAR ${ }^{-/-}$mice (Figure 4(a)). These decreases by pioglitazone were not observed in $\mathrm{HF}$-fed $\mathrm{CAR}^{+/+}$mice. Particularly, SCD-1 expression was increased in pioglitazonetreated $\mathrm{CAR}^{+/+}$mice, but significantly decreased in HF-fed pioglitazone-treated $\mathrm{CAR}^{-/-}$mice. In addition, the expression of CD36, which is important for fatty acid uptake, was increased after pioglitazone treatment in the chow diet, but the increase was not observed in HF-fed $\mathrm{CAR}^{-/-}$mice (Figure 4(a)). Because both SCD-1 and CD36 were regulated by PPAR $\gamma$, the expression of PPAR $\gamma 1, \operatorname{PPAR} \gamma 2$, and PGC1 $\alpha$ was evaluated; interestingly, the expression of PPAR $\gamma 2$ and PGCl $\alpha$ was decreased only in HF-fed pioglitazone-treated $\mathrm{CAR}^{-/-}$mice (Figure 4(b)). The expression of fatty acid oxidation-related genes did not differ among $\mathrm{HF}$-fed $\mathrm{CAR}^{+/+}$ and $\mathrm{CAR}^{-1-}$ mice, except PPAR $\alpha$; the expression of PPAR $\alpha$ was decreased by pioglitazone or CAR deletion under HF-fed conditions (Figure 4(b)).

\subsection{Acute Changes in Gene Expression after Pioglitazone Treat-} ment in $C A R^{-/-}$Mice. To determine whether the changes in gene expression were primary or secondary responses after long-term of treatment with the HF diet or pioglitazone, we analyzed the expression of SREBP-1c, SCD-1, CD36, $\operatorname{PPAR} \gamma 2$, and PCG1 $\alpha$ at $6 \mathrm{~h}$ after pioglitazone treatment combined with vehicle or lipid injection (Figure 5). The expression of SREBP-1c was increased in $\mathrm{CAR}^{-/-}$mice and 

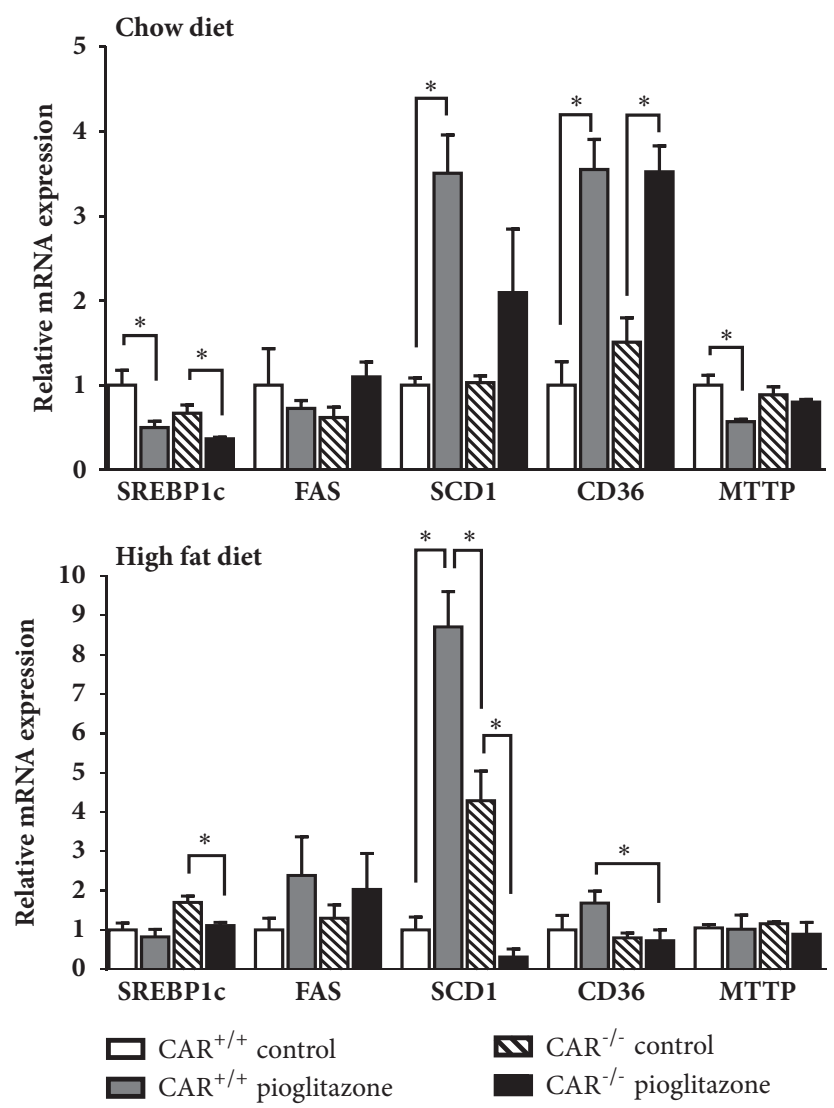

(a)
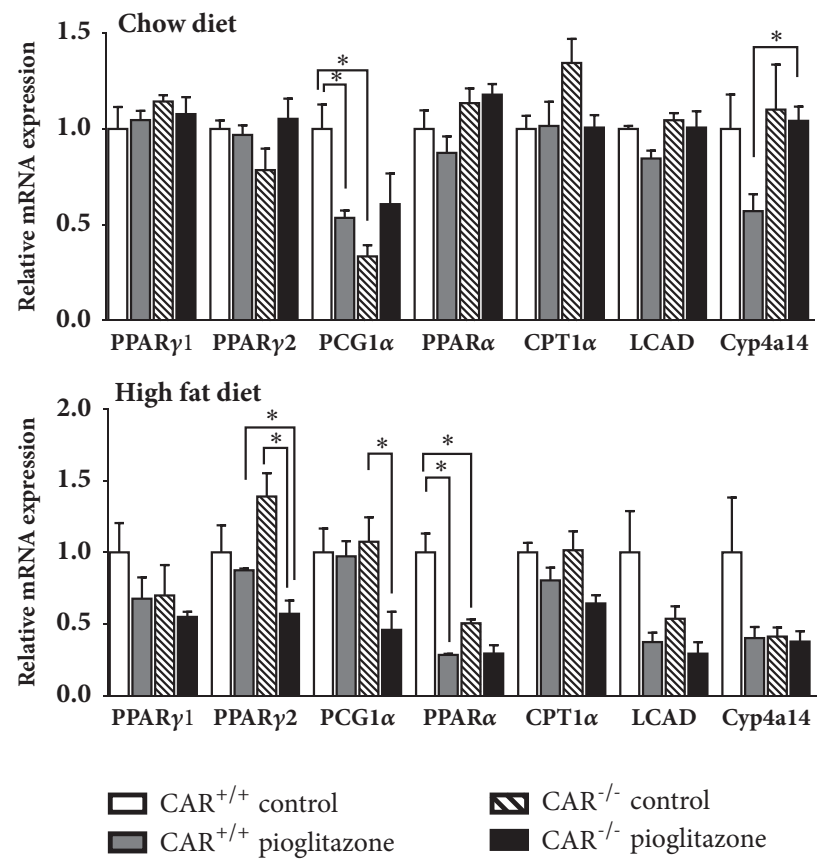

(b)

FIGURE 4: Gene expression related to fatty liver of $\mathrm{CAR}^{+/+}$and $\mathrm{CAR}^{-/-}$mice after 12 weeks of pioglitazone treatment in chow and high-fat diet condition. (a) Difference in expression of genes involved in lipogenesis, SREBP-1c, FAS, and SCD-1, and lipid uptake, CD36 and MTTP. (b) Difference in expression of PPARs and PGC1 $\alpha$ and genes involved in fatty acid oxidation, CPT1 $\alpha$, LCAD, and CYP4A14. $* \mathrm{p}<0.05$. CD 36 , cluster of differentiation 36 ; CPT $1 \alpha$, carnitine palmitoyltransferase $1 \alpha$; CYP4A14, cytochrome P450, family 4 , subfamily a, polypeptide 14; FAS, fatty acid synthase; LCAD, long-chain acyl-CoA dehydrogenase; MTTP, microsomal triglyceride transfer protein; PGC1 $\alpha$, peroxisome proliferator-activated receptor $\gamma$ coactivator $1 \alpha$; PPAR, peroxisome proliferator-activated receptor; SREBP-1c, sterolregulatory element binding protein-1c; SCD-1, stearoyl-CoA desaturase. 

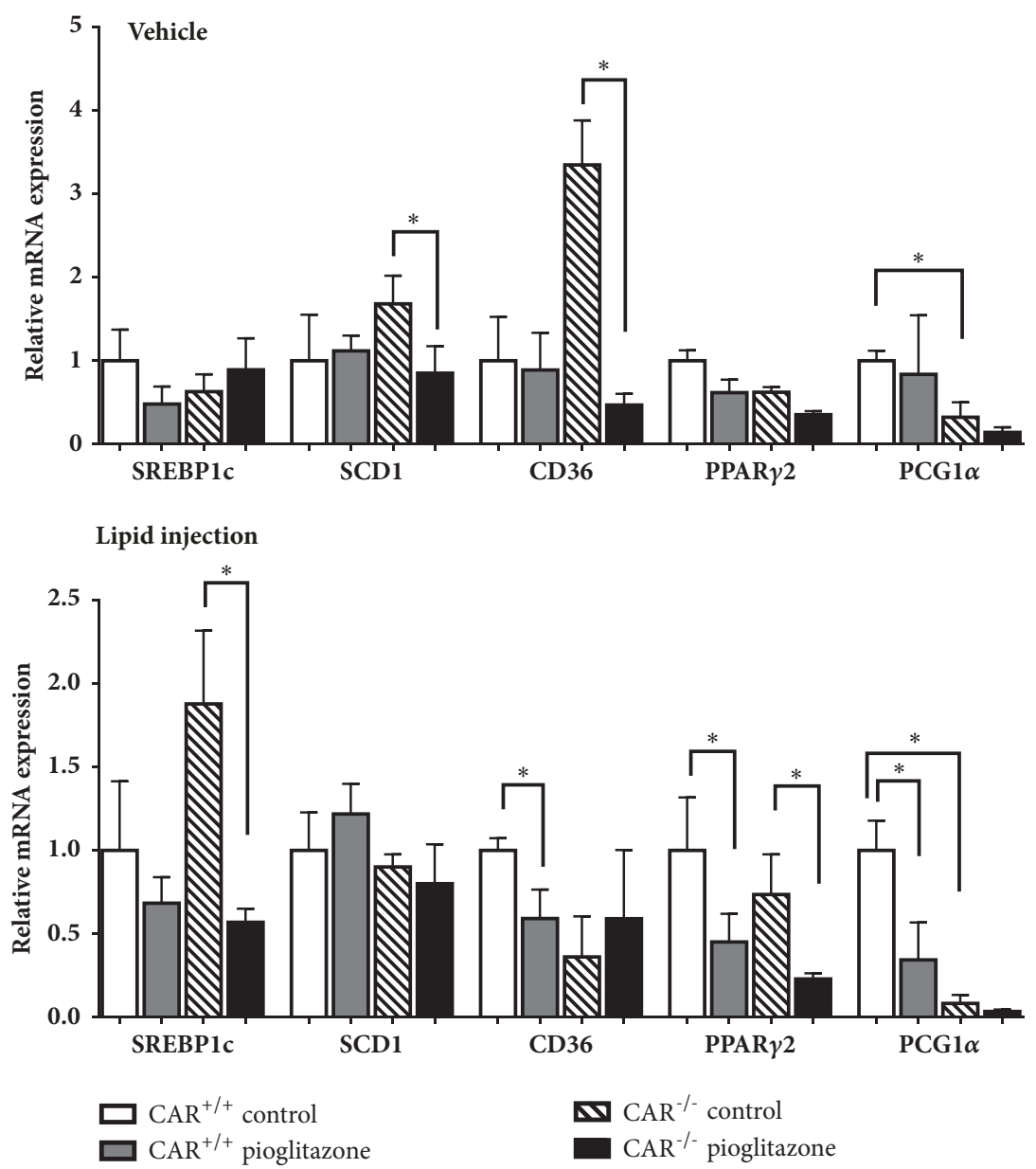

FIGURE 5: Expression of five genes (SREBP-1c, SCD-1, CD36, PPAR $\gamma 2$, and PGC1 $\alpha$ ) in $\mathrm{CAR}^{+/+}$and CAR ${ }^{-/-}$mice after $6 \mathrm{~h}$ pioglitazone and lipid administration via intraperitoneal injection. $* \mathrm{p}<0.05$. CD36, cluster of differentiation 36 ; PGC1 $\alpha$, peroxisome proliferator-activated receptor $\gamma$ coactivator $1 \alpha$; PPAR $\gamma 2$, peroxisome proliferator-activated receptor $\gamma 2$; SREBP-1c, sterol-regulatory element binding protein-1c; SCD-1, stearoyl-CoA desaturase.

significantly decreased by pioglitazone combined with lipid injection. This change was like that observed in 12 -week HFfed mice. The expression of SCD-1 and CD36 was decreased in pioglitazone-treated $\mathrm{CAR}^{-/-}$mice with vehicle injection, but this change was not observed in $\mathrm{CAR}^{-/-}$mice with lipid injection. PPAR $\gamma 2$ expression was significantly decreased by pioglitazone in both $\mathrm{CAR}^{+/+}$and $\mathrm{CAR}^{-/-}$mice with lipid injection. The expression of PGCl $\alpha$ was decreased in $\mathrm{CAR}^{-/-}$ mice, regardless of lipid injection.

\section{Discussion}

In this study, we evaluated the effect of pioglitazone on NAFLD mediated by CAR deletion in the mouse liver. Our results showed that NAFLD was significantly improved by pioglitazone in a CAR deletion state. This effect was not due to the elevated serum concentration of pioglitazone resulting from decreased degradation by CAR deletion.

CAR agonism has been shown to improve fatty liver and insulin resistance [18]. In contrast, in the absence of
CAR, there was no improvement in fatty liver, as shown in Figure 2(d), and these results were confirmed in another study [16]. Therefore, it is likely that the improvement of fatty liver in pioglitazone-treated CARKO mice is not due to CAR deletion itself but rather because of the interaction of several genes involved in fatty liver in the absence of CAR.

Genetic analysis revealed that CD36 and SCD-1 expression was significantly decreased by pioglitazone in 12 -week $\mathrm{HF}$-fed $\mathrm{CAR}^{-/-}$mice and these changes may have contributed to the removal of liver fat. Recent findings suggested that increased hepatic CD36 activity is critical for the development of steatosis under pathologic conditions such as HF diet, obesity, and diabetes $[19,20]$. In contrast, when CD36 was deleted, the liver was protected from NAFLD development [21]. SCD-1 is an endoplasmic reticulum enzyme that catalyzes the biosynthesis of monounsaturated fatty acids from saturated fatty acids [22]. Hepatic SCD-1 activity is increased in NAFLD [23]. Mice with liver-specific knockout of SCD1 are protected from carbohydrate-induced adiposity and hepatic steatosis [24]. These results suggest that deceased expression of CD36 and SCD-1 protects against hepatic 
steatosis. However, the responses of SCD-1 and CD36 differed in 12-week (long-term) and 6-h (short-term) administration of pioglitazone in $\mathrm{CAR}^{-/-}$mice. Therefore, the changes in SCD-1 and CD36 are likely a secondary response.

In contrast, the expression of SREBP-1c in $\mathrm{CAR}^{-/-}$mice fed a HF diet was consistently decreased by pioglitazone in both the 12-week and 6-h experiments, suggesting that decreased expression of SREBP-1c has a primary effect on the reduction of hepatic steatosis. In addition, the change in the pattern of PPAR $\gamma 2$ was similar to that in SREBP-1c, suggesting that these genes are closely related, which has been demonstrated previously [25]. We also found that HF diet itself increases the expression of SREBP1c and PPAR $\gamma 2$ in the liver (Supplementary Figure 2). Therefore, the decreased expression of SREBP-1c and PPAR $\gamma 2$ by pioglitazone in HFfed $\mathrm{CAR}^{-/-}$mice played a major role in improving hepatic steatosis.

Several studies examining the effects of PPAR $\gamma$ on NAFLD have demonstrated enhanced expression of lipogenic genes and increased expression of PPAR $\gamma$ in animal models of steatotic liver [26-28]. Moreover, a role for PPAR $\gamma$ has been established in the maintenance of a steatotic phenotype in the liver [27]. In a previous study using a hepatic stable cell line expressing PPAR $\gamma 2$, PPAR $\gamma 2$ expression induced lipid accumulation in hepatocytes by upregulating adipogenic and lipogenic gene expression [29]. Culturing of PPAR $\gamma 2$ expressing hepatocytes in the absence of serum (exogenous lipids) resulted in lipid accumulation, suggesting that de novo lipid synthesis is an important mechanism contributing to steatosis in hepatocytes [29].

Interestingly, pioglitazone did not improve fatty liver in HF-fed $\mathrm{CAR}^{+/+}$mice, despite improvements in blood glucose level. This effect was also demonstrated in other murine studies. C57BL6 ob/ob mice treated with rosiglitazone $(1 \mathrm{mg} / \mathrm{kg})$ for 12 weeks showed significantly increased hepatic steatosis and the NAFLD activity score was significantly higher in rosiglitazone-treated mice than in untreated ob/ob mice [30]. Oral administration of pioglitazone for 28 days also worsened hepatic steatosis in KKAy mice [31]. In addition, $\operatorname{PPAR} \gamma 1$ overexpression in the liver of PPAR $\alpha^{-/-}$mice showed increased fat accumulation in the liver [28]. These results suggest that the effects of PPAR $\gamma$ agonist on fatty liver may differ in humans and mice.

A limitation of this study was that we were not able to determine the exact molecular mechanism of the interaction between PPAR $\gamma 2$ and CAR. A summary figure of our result is presented in Supplementary Figure 3. Further studies are needed to reveal the underlying mechanisms. However, our study results might be valuable because they suggest that interaction with CAR and pioglitazone/PPAR $\gamma 2$ may be important in regulating gene expression associated with NAFLD.

\section{Data Availability}

The data used to support the findings of this study are included within the article.

\section{Conflicts of Interest}

The authors declare that they have no conflicts of interest.

\section{Acknowledgments}

We are very grateful to So Yeon Park for helping to make paraffin blocks and slides. This work was supported by a grant (Hwa Young Ahn, 2011) from the Korean Diabetes Association and a grant from National Research Foundation of the Ministry of Education, Science and Technology of Korea (2010-0023068).

\section{Supplementary Materials}

Supplementary Figure 1: the expression of CYP2B10 and CYP3A11 after 12 weeks of pioglitazone treatments in $\mathrm{CAR}^{+/+}$ mice with $\mathrm{HF}$ diet. $* \mathrm{p}<0.05$. Supplementary Figure 2: difference of expression of genes (SREBP1c, SCD-1, CD36, and PPAR $\gamma 2$ ) by HF diet in $\mathrm{CAR}^{+/+}$mice. $* \mathrm{p}<0.05$. Supplementary Figure 3: summary figure of improvement of fatty liver by interaction of PPAR $\gamma 2$, SREBP1c, and CAR. (Supplementary Materials)

\section{References}

[1] E. L. Anderson, L. D. Howe, H. E. Jones, J. P. T. Higgins, D. A. Lawlor, and A. Fraser, "The prevalence of non-alcoholic fatty liver disease in children and adolescents: A systematic review and meta-analysis," PLoS ONE, vol. 10, no. 10, Article ID e0140908, 2015.

[2] P. Angulo, "Nonalcoholic fatty liver disease," The New England Journal of Medicine, vol. 346, no. 16, pp. 1221-1231, 2002.

[3] M. E. Rinella, "Nonalcoholic fatty liver disease: a systematic review," The Journal of the American Medical Association, vol. 313, no. 22, pp. 2263-2273, 2015.

[4] G. Marchesini, M. Brizi, A. M. Morselli-Labate et al., "Association of nonalcoholic fatty liver disease with insulin resistance," American Journal of Medicine, vol. 107, no. 5, pp. 450-455, 1999.

[5] K. Cusi, B. Orsak, F. Bril et al., "Long-term pioglitazone treatment for patients with nonalcoholic steatohepatitis and prediabetes or type 2 diabetes mellitus a randomized trial," Annals of Internal Medicine, vol. 165, no. 5, pp. 305-315, 2016.

[6] S. Shadid and M. D. Jensen, "Effect of pioglitazone on biochemical indices of non-alcoholic fatty liver disease in upper body obesity," Clinical Gastroenterology and Hepatology, vol. 1, no. 5, pp. 384-387, 2003.

[7] Y. Miyazaki, A. Mahankali, M. Matsuda et al., "Improved glycemic control and enhanced insulin sensitivity in type 2 diabetic subjects treated with pioglitazone," Diabetes Care, vol. 24, no. 4, pp. 710-719, 2001.

[8] J. Berger and D. E. Moller, "The mechanisms of action of PPARs," Annual Review of Medicine, vol. 53, pp. 409-435, 2002.

[9] D. Eckland and M. Danhof, "Clinical pharmacokinetics of pioglitazone," Experimental and Clinical Endocrinology \& Diabetes, vol. 108, no. Sup. 2, pp. 234-242, 2001.

[10] M. Hanefeld, "Pharmacokinetics and clinical efficacy of pioglitazone," International Journal of Clinical Practice Supplement, no. 121, pp. 19-25, 2001. 
[11] A. di Masi, E. D. Marinis, P. Ascenzi, and M. Marino, "Nuclear receptors CAR and PXR: Molecular, functional, and biomedical aspects," Molecular Aspects of Medicine, vol. 30, no. 5, pp. 297343, 2009.

[12] J. Zhang, W. Huang, S. S. Chua, P. Wei, and D. D. Moore, "Modulation of acetaminophen-induced hepatotoxicity by the xenobiotic receptor CAR," Science, vol. 298, no. 5592, pp. 422424, 2002.

[13] E. S. Baskin-Rey, A. Anan, H. Isomoto, S. F. Bronk, and G. J. Gores, "Constitutive androstane receptor agonist, TCPOBOP, attenuates steatohepatitis in the methionine choline-deficient diet-fed mouse," World Journal of Gastroenterology, vol. 13, no. 42, pp. 5635-5641, 2007.

[14] M. C. Cave, H. B. Clair, J. E. Hardesty et al., "Nuclear receptors and nonalcoholic fatty liver disease," Biochimica et Biophysica Acta (BBA)-Gene Regulatory Mechanisms, vol. 1859, no. 9, pp. 1083-1099, 2016.

[15] P. Wei, J. Zhang, M. Egan-Hafley, S. Liang, and D. D. Moore, "The nuclear receptor CAR mediates specific xenobiotic induction of drug metabolism," Nature, vol. 407, no. 6806, pp. 920923, 2000.

[16] B. Dong, P. K. Saha, W. Huang et al., "Activation of nuclear receptor CAR ameliorates diabetes and fatty liver disease," Proceedings of the National Acadamy of Sciences of the United States of America, vol. 106, no. 44, pp. 18831-18836, 2009.

[17] T. Jaakkola, J. Laitila, P. J. Neuvonen, and J. T. Backman, "Pioglitazone is metabolised by CYP2C8 and CYP3A4 in vitro: Potential for interactions with CYP2C8 inhibitors," Basic \& Clinical Pharmacology \& Toxicology, vol. 99, no. 1, pp. 44-51, 2006.

[18] A. Moreau, M. J. Vilarem, P. Maurel, and J. M. Pascussi, "Xenoreceptors CAR and PXR activation and consequences on lipid metabolism, glucose homeostasis, and inflammatory response," Molecular Pharmaceutics, vol. 5, no. 1, pp. 35-41, 2008.

[19] D. P. Y. Koonen, R. L. Jacobs, and M. Febbraio, "Increased hepatic CD36 expression contributes to dyslipidemia associated with diet-induced obesity," Diabetes, vol. 56, no. 12, pp. $2863-$ 2871, 2007.

[20] J. J. F. P. Luiken, Y. Arumugam, D. J. Dyck et al., "Increased Rates of Fatty Acid Uptake and Plasmalemmal Fatty Acid Transporters in Obese Zucker Rats," The Journal of Biological Chemistry, vol. 276, no. 44, pp. 40567-40573, 2001.

[21] J. Zhou, M. Febbraio, T. Wada et al., "Hepatic fatty acid transporter Cd36 is a common target of LXR, PXR, and PPAR $\gamma$ in promoting steatosis," Gastroenterology, vol. 134, no. 2, pp. 556-567, 2008.

[22] C. M. Paton and J. M. Ntambi, "Biochemical and physiological function of stearoyl-CoA desaturase," American Journal of Physiology-Endocrinology and Metabolism, vol. 297, no. 1, pp. E28-E37, 2009.

[23] A. Kotronen, T. Seppänen-Laakso, J. Westerbacka et al., "Hepatic stearoyl-CoA desaturase (SCD)-1 activity and diacylglycerol but not ceramide concentrations are increased in the nonalcoholic human fatty liver," Diabetes, vol. 58, no. 1, pp. 203208, 2009.

[24] M. Miyazaki, M. T. Flowers, H. Sampath et al., "Hepatic Stearoyl-CoA Desaturase-1 Deficiency Protects Mice from Carbohydrate-Induced Adiposity and Hepatic Steatosis," Cell Metabolism, vol. 6, no. 6, pp. 484-496, 2007.
[25] P. Pettinelli and L. A. Videla, "Up-regulation of PPAR- $\gamma$ mRNA expression in the liver of obese patients: an additional reinforcing lipogenic mechanism to SREBP-1c induction," The Journal of Clinical Endocrinology \& Metabolism, vol. 96, no. 5, pp. 14241430, 2011.

[26] O. Gavrilova, M. Haluzik, K. Matsusue et al., "Liver peroxisome proliferator-activated receptor $\gamma$ contributes to hepatic steatosis, triglyceride clearance, and regulation of body fat mass," The Journal of Biological Chemistry, vol. 278, no. 36, pp. 3426834276, 2003.

[27] K. Matsusue, M. Haluzik, G. Lambert et al., "Liver-specific disruption of PPAR $\gamma$ in leptin-deficient mice improves fatty liver but aggravates diabetic phenotypes," The Journal of Clinical Investigation, vol. 111, no. 5, pp. 737-747, 2003.

[28] S. Yu, K. Matsusue, P. Kashireddy et al., "Adipocyte-specific gene expression and adipogenic steatosis in the mouse liver due to peroxisome proliferator-activated receptor gammal (PPARgamma1) overexpression," The Journal of Biological Chemistry, vol. 278, no. 1, pp. 498-505, 2003.

[29] S. E. Schadinger, N. L. R. Bucher, B. M. Schreiber, and S. R. Farmer, "PPAR 22 regulates lipogenesis and lipid accumulation in steatotic hepatocytes," American Journal of PhysiologyEndocrinology and Metabolism, vol. 288, no. 6, pp. E1195-E1205, 2005.

[30] I. García-Ruiz, C. Rodríguez-Juan, T. Díaz-Sanjuán, M. Á. Martínez, T. Muñoz-Yagüe, and J. A. Solís-Herruzo, "Effects of rosiglitazone on the liver histology and mitochondrial function in ob/ob mice," Hepatology, vol. 46, no. 2, pp. 414-423, 2007.

[31] J. Oribe, T. Kakuma, M. Haranaka, K. Okamoto, M. Seike, and $\mathrm{H}$. Yoshimatsu, "Intraperitoneal administration attenuates thiazolidinedione-induced hepatic steatosis in KKAy mice with increased hepatic peroxisome proliferator-activated receptor (PPAR) $\gamma$ mRNA expression," Obesity Research \& Clinical Practice, vol. 6, no. 3, pp. e249-e261, 2012. 


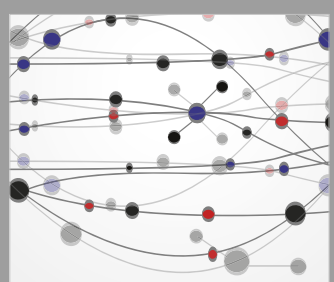

The Scientific World Journal
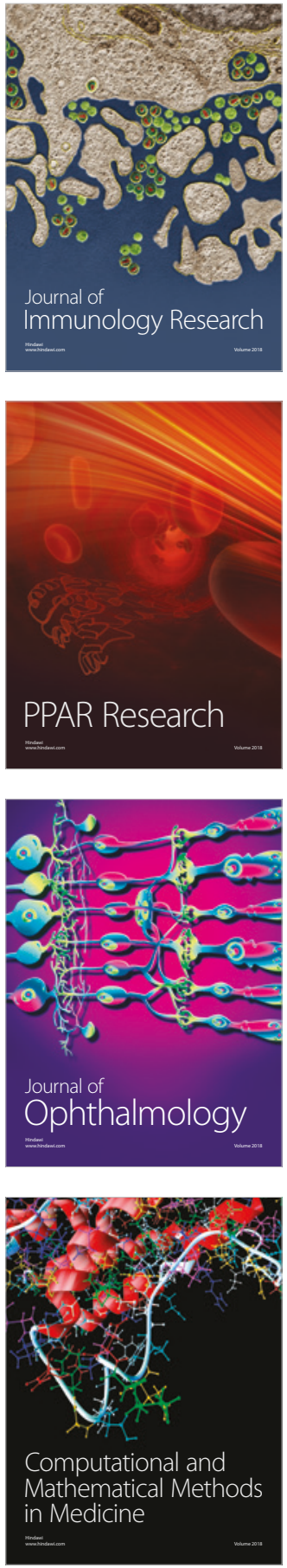

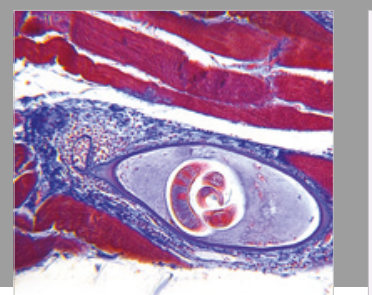

Gastroenterology Research and Practice

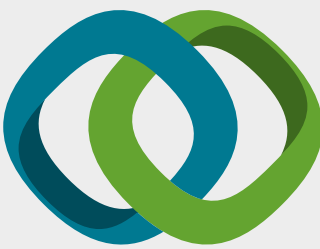

\section{Hindawi}

Submit your manuscripts at

www.hindawi.com
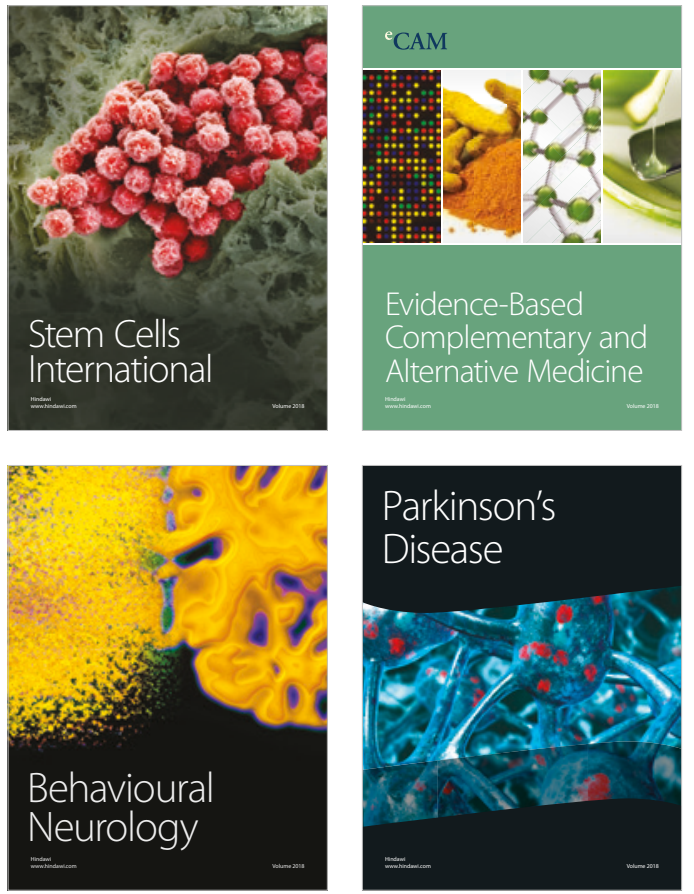

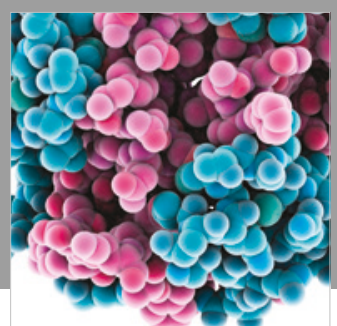

ournal of

Diabetes Research

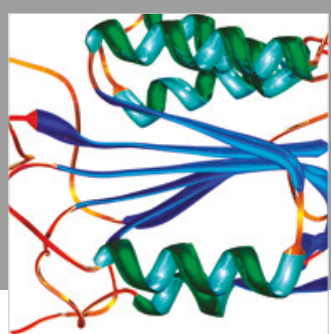

Disease Markers
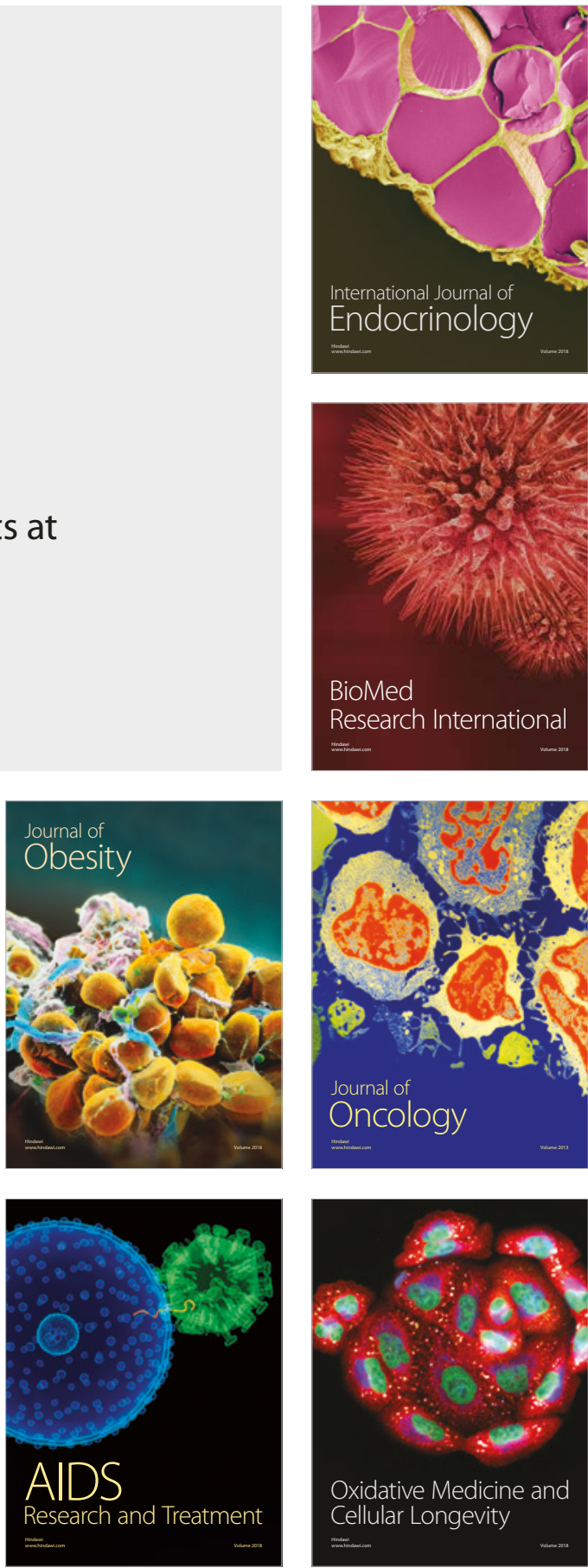